\title{
O cerrado não é um bioma
}

\author{
Marco Antônio Batalha ${ }^{1,2}$ \\ ${ }^{1}$ Departamento de Botânica, Universidade Federal de São Carlos - UFSCar, \\ CP 676, CEP 13565-905, São Carlos, SP, Brasil \\ ${ }^{2}$ Autor para correspondência: Marco Antônio Batalha, e-mail: marcobat@uol.com.br
}

BATALHA, M.A. The Brazilian cerrado is not a biome. Biota Neotrop. 11(1): http://www.biotaneotropica.org. br/v11n1/en/abstract?inventory+bn00111012011.

Abstract: It is important to define correctly a given concept, because there may be immediate and practical
implications. Two important concepts to be accurately defined are "cerrado" and "biome". As used in Brazil, the
concept of biome has erroneously acquired a floristic meaning. As a matter of fact, the concept of biome is close
to that of vegetation form, but takes into account the association between the vegetation and the animals and
microorganisms. Thus, on the one hand, the concept of biome is physiognomic and functional, that is, it takes
into account the general aspect of the vegetation, growth patterns, and reproduction patterns; on the other hand,
it is not floristic, that is, the taxonomic affinities of the species that occur in different regions of the same biome
are irrelevant. To be coherent with international literature and use accurately the concept of biome, we should
consider the Brazilian cerrado as being composed of three biomes: tropical grassland (campo limpo), savanna
(campo sujo, campo cerrado, and cerrado sensu stricto), and seasonal forest (cerradão). Keywords: physiognomy, savanna, terminology, vegetation form.

BATALHA, M.A. O cerrado não é um bioma. Biota Neotrop. 11(1): http://www.biotaneotropica.org.br/v11n1/ pt/abstract?inventory+bn00111012011.

Resumo: É importante definirmos corretamente um termo, porque pode haver implicações práticas e imediatas. Dois conceitos importantes para serem definidos acuradamente são os de "cerrado" e de "bioma". Da maneira como vem sendo usado no Brasil, o conceito de bioma adquiriu erroneamente uma conotação florística. Na verdade, o conceito de bioma é similar ao de formação vegetal, mas leva em conta a associação da vegetação com a fauna e com os microrganismos. Assim, por um lado, o conceito de bioma é fisionômico e funcional, isto é, levam-se em conta a aparência geral da vegetação e aspectos como os ritmos de crescimento e reprodução; por outro, o conceito não é florístico, isto é, a afinidade taxonômica das espécies que aparecem em várias unidades de um mesmo bioma é irrelevante. Para sermos coerentes com toda a literatura internacional e usarmos o conceito de bioma acuradamente, devemos considerar o cerrado sensu lato como formado por três biomas: o campo tropical (campo limpo), a savana (campo sujo, campo cerrado e cerrado sensu stricto) e a floresta estacional (cerradão).

Palavras-chave: fisionomia, savana, terminologia, formação vegetal. 
“A acurácia da língua é uma das fortalezas da verdade.” (Anna Jameson)

\section{Introdução}

Nosso planeta apresenta um padrão complexo de climas, os quais, por sua vez, têm um papel importante na criação dos padrões complexos de vegetação e tipos de comunidades que nele encontramos. Os ecólogos dividem esses padrões de grande escala em unidades denominadas biomas, as mais amplas comunidades bióticas reconhecidas em nível geográfico, definidos como subdivisões biológicas que refletem as características funcionais e fisionômicas da vegetação (Oxford 2004). A distribuição dos biomas na superfície terrestre relaciona-se principalmente com os climas $\mathrm{e}$, dentre os seus elementos, mais diretamente com a temperatura e a precipitação, seja a quantidade de chuva, seja a sua distribuição ao longo do ano (Walter 1986). Ao empregar uma abordagem fisionômica da vegetação, Raunkiaer (1934) mostrou ser possível definir e caracterizar unidades ecológicas, inicialmente referidas como formações vegetais, por serem baseadas exclusivamente em critérios botânicos, em que a aparência da vegetação e as formas de vida predominantes são uniformes. Essa forma das plantas foi reconhecida como o modo mais eficaz de definir os biomas em relação a qualquer outro sistema de classificação taxonômico ou evolutivo. O conceito de bioma é similar ao de formação vegetal, mas leva em conta a associação da vegetação com a fauna e com os microrganismos (Box \& Fujiawara 2005). Assim, um bioma corresponde, grosso modo, a uma formação vegetal, porém inclui não só as plantas, mas também os demais organismos (Maarel 2005). Cada bioma tem uma fisionomia característica, compreendendo altura e hábito de crescimento dos principais táxons, tamanho, forma e textura das folhas, proporção de plantas sempreverdes e decíduas, diversidade de espécies e outros fatores que impõem fisionomia e arquitetura características para amplas extensões da cobertura vegetal (Tallis 1991).

\section{Um Erro Enraizado}

O cerrado é considerado um dos pontos quentes (hot spots) para a conservação da biodiversidade no mundo (Myers et al. 2000). Mas que cerrado? O cerrado enquanto domínio fitogeográfico? O cerrado enquanto bioma? O cerrado enquanto tipo vegetacional? O cerrado enquanto fisionomia? Como podemos ver, é importante definirmos corretamente um termo, porque pode haver implicações práticas e imediatas. Dois conceitos importantes para serem definidos acuradamente são os de "cerrado" e de "bioma". Da maneira como vem sendo usado no Brasil, o conceito de bioma adquiriu erroneamente uma conotação florística. Usado dessa maneira errônea por biólogos, não por acaso passou a ser usado equivocadamente por um público mais amplo, como agências governamentais e organizações nãogovernamentais. Hoje em dia, esse erro está enraizado. Coutinho (2006) chamou a atenção para esse problema e teve a oportunidade de resolvê-lo, mas sua argumentação em alguns pontos é contraditória. Embore apresente as premissas corretamente, Coutinho (2006) chama o cerrado ora de um único bioma (por exemplo, "O bioma Cerrado merece aqui uma discussão um pouco mais longa.", p. 19), ora de um complexo de biomas (por exemplo, "[...]pode-se dizer que o Cerrado não é um bioma único, mas um complexo de biomas.", p. 19). Como argumentarei, esse segundo ponto de vista é o correto e, portanto, o cerrado não é um único bioma - como vem sendo rotineiramente tratado -, mas um complexo de biomas.

A ciência gera jargões, e essa terminologia especializada é necessária para expressarmos ideias novas e complexas de forma clara e sucinta (Peters 1991). Cada parte de uma teoria começa como um conceito, e conceitos fracos são difíceis de serem erradicados (Peters 1991). Na ausência de uma definição clara, diferentes usuários do termo podem desenvolver definições independentes e até inconsistentes, fazendo, ao longo do tempo, com que o conceito traga consigo tantos significados que acaba se transformando em um "nãoconceito" (Hurlbert 1971). Quando a linguagem é desvalorizada ou usada erroneamente, também o são aqueles que a usam (Orr 1999). Uma vez que a linguagem é a única moeda onde quer que se persiga a verdade, não deve haver prioridade maior para a comunidade científica do que defender a clareza e a integridade de seus conceitos (Orr 1999). O criticismo científico encoraja a operacionalização de conceitos, identificando as capacidades, funções e limitações atuais de conceitos existentes (Peters 1991). Sendo assim, dada a importância de definirmos termos claramente e dada a importância dos conceitos de cerrado e de bioma, pretendo discuti-los e sugerir um uso acurado deles.

\section{O Conceito de Bioma}

Uma excelente revisão do conceito de bioma foi feita por Coutinho (2006). Relembro algumas das definições apresentadas nesse trabalho de Coutinho (2006) para tornar minha argumentação clara. Clapham Jr. (1973, p. 14) disse que "[...] a distribuição dos biomas é controlada em última instância por fatores ambientais abióticos - especialmente o clima - e um dado bioma pode ser formado em várias diferentes partes do mundo." Dajoz (1973, p. 280) escreveu que "[...] b bioma é um agrupamento de fisionomia homogênea e independente da composição florística." Crawley (1989, p. 27) disse que "[...]os grandes biomas do mundo mostram um grau de convergência notável, apesar das amplas diferenças na afinidade taxonômica das suas floras." Cox \& Moore (1993, p. 8) também enfatizaram que o conceito de bioma é biogeográfico e não taxonômico, e que "[...] embora as savanas tropicais do Brasil, Quênia, Índia e Tailândia compreendam espécies diferentes de plantas e animais, elas têm muito em comum em termos de suas arquiteturas, crescimentos e produtividades estacionais, formas de vida de animais e plantas e as maneiras pelas quais têm sido usadas pela população humana." No próprio conceito de Walter (1986), adotado por Coutinho (2006), está claro que um mesmo tipo de bioma pode aparecer em áreas distintas geograficamente.

Além disso, em um dicionário de Biologia (Oxford 1996, p. 72), encontramos a seguinte definição de bioma: "Uma comunidade ou complexo de comunidades ecológicas que se estende por uma ampla área geográfica caracterizada por um tipo dominante de vegetação. Os organismos de um bioma estão adaptados às condições climáticas associadas à região. Não há fronteiras bem definidas entre biomas adjacentes, que se fundem gradualmente uns com os outros. Exemplos de biomas são tundra, floresta pluvial tropical, taigá, chaparral, campos (temperados e tropicais) e deserto". Em um dicionário de Ecologia (Oxford 2004, p. 56), encontramos uma definição semelhante: "Uma subdivisão biológica que reflete o caráter fisionômico e ecológico da vegetação. Biomas são as maiores comunidades bióticas e geográficas que são convenientes de serem reconhecidas. Eles correspondem, grosso modo, às regiões climáticas, ainda que outros controles ambientais sejam algumas vezes importantes. Eles são equivalentes ao conceito de principais formações vegetais na Ecologia Vegetal, mas são definidos em termos de todos os organismos vivos e de suas interações com o meio (e não apenas com o tipo de vegetação dominante). Tipicamente, biomas distintos são reconhecidos para todas as principais regiões climáticas no mundo, enfatizando as adaptações dos organismos aos seus ambientes, e.g., bioma das florestas tropicais pluviais, bioma dos desertos, bioma das tundras".

Sendo assim, dos diversos conceitos de bioma apresentados, podemos ressaltar alguns pontos que são comuns e se sobressaem: 1) o conceito de bioma é fisionômico, isto é, leva-se em conta a aparência geral da vegetação, resultante do predomínio de certas formas de vida; 2) o conceito de bioma é funcional, isto é, levam-se em conta 
aspectos como os ritmos de crescimento e reprodução; 3) o conceito de bioma não é florístico, isto é, a afinidade taxonômica das espécies que aparecem em várias unidades de um mesmo bioma é irrelevante; 4) o conceito de bioma é delimitado pela vegetação, mas engloba além dela, toda a demais biota; e 5) o conceito de bioma é aplicável à Terra como um todo e não a esta ou àquela região.

\section{O Conceito de Cerrado}

Há dois principais sistemas usados para classificar a vegetação, um baseado em descritores funcionais e fisionômicos e outro baseado em relações florísticas (Joly et al. 1999). Das definições de bioma apresentadas acima, inferimos que só há sentido em se usar esse conceito quando a classificação da vegetação é funcional-fisionômica. Nesse caso, por coerência, devem-se usar termos aplicáveis à vegetação mundial. Há termos usados na classificação da vegetação brasileira que são carregados floristicamente, isto é, quando nos referimos, por exemplo, ao "cerrado", "à "caatinga" ou ao "pampa", estamos nos remetendo a certas espécies vegetais características.

Coutinho (2006) afirma corretamente que, dentro dos domínios fitogeográficos, encontramos vários biomas. Dessa forma, o "domínio amazônico não é, portanto, um bioma único”, mas sim "um mosaico de biomas" (Coutinho 2006, p. 18). O problema aparece quando o autor discute o cerrado. Em um primeiro momento, citando um trabalho anterior (Coutinho 2006, p. 19), ele diz que o cerrado seria "[...]um complexo de biomas, distribuídos em mosaico." Concordo com essa visão. Justamente por sua variação fisionômica, indo do campo limpo (bioma dos campos tropicais), passando pelas fisionomias intermediárias (bioma das savanas) e chegando ao cerradão (bioma das florestas estacionais), o cerrado sensu lato não pode ser considerado um único bioma, mas sim um complexo de biomas, mais especificamente três.

Coutinho (2006, p. 19) até sugere essa posição escrevendo que "[...]caso se queira ser absolutamente fiel ao conceito de bioma adotado pelos diversos autores mencionados adrede, pode-se dizer que o cerrado não é um bioma único, mas um complexo de biomas." Entretanto, contrariamente à sua argumentação anterior, Coutinho (2006) alega que todas as savanas do mundo tem essa complexidade fisionômica e, ainda assim, são consideradas um único bioma pela grande maioria dos autores e que, portanto, ao se considerar o cerrado como um bioma de savana, não se foge ao conceito da maioria dos autores internacionais. Esse erro se enraizou, com o oxímoro "bioma cerrado" se tornando onipresente, aparecendo quase como um substantivo composto, só faltando o hífen para tal.

Para sermos coerentes com toda a literatura internacional e usarmos o conceito de bioma acuradamente, devemos considerar o cerrado sensu lato como formado por três biomas: o campo tropical, a savana e a floresta estacional. Campos tropicais são formações tropicais em que o estrato herbáceo é contínuo, com pequenos arbustos em baixas densidades (Woodward 2008). Se seguirmos a classificação fisionômica de Coutinho (1978), incluímos no bioma de campo tropical o campo limpo. Já as savanas são formações tropicais em que o estrato herbáceo é quase contínuo, interrompido apenas por arbustos e árvores em densidades variáveis, e em que os principais padrões de crescimento estão associados às estações úmidas e secas alternantes (Bourlière \& Hadley 1983). No bioma de savana, portanto, incluímos o campo sujo, o campo cerrado e o cerrado sensu stricto. Florestas estacionais são formações em que predominam árvores de maior porte, cujas copas formam um dossel e cujos principais padrões de crescimento também estão associados às estações úmidas e secas alternantes (Woodward 2008). No bioma de floresta estacional, incluímos, pois, o cerradão. Como há uma unidade florística entre as diversas fisionomias do cerrado (Coutinho
1978), devemos considerá-lo um único tipo vegetacional, já que as afinidades taxonômicas são levadas em conta nesse caso.

Cabe ainda ressaltar que, dentro de um domínio fitogeográfico, isto é, uma área do espaço geográfico, com dimensões subcontinentais, em que predominam características morfoclimáticas semelhantes e um certo tipo de vegetação, há vários tipos vegetacionais. Assim, dentro do domínio do Cerrado, além do cerrado como tipo vegetacional dominante, há outros tipos vegetacionais, como a floresta ripícola, o campo rupícola, a floresta estacional semidecídua, a floresta estacional decídua, o campo úmido, entre outros. Cada um desses tipos vegetacionais tem sua flora característica e daí a razão de distingui-los. No caso do cerrado em particular, dada a sua grande variação fisionômica, encontramos não um, mas sim três biomas. Isso tem implicações práticas e imediatas para a conservação. Por exemplo, recentemente aprovou-se no estado de São Paulo (2009) uma lei que visa a proteger o cerrado, mas que não contempla as suas fisionomias abertas. Dessa forma, todo um bioma que compõe o cerrado, o bioma de campo tropical, não está contemplado pela lei.

Assim, podemos usar a palavra "cerrado" em três sentidos: 1) Cerrado, com a inicial maiúscula, quando estivermos nos referindo ao domínio fitogeográfico do Cerrado, incluindo não só o cerrado sensu lato, mas também os outros tipos vegetacionais que ali se encontram; 2) cerrado sensu lato ou simplesmente cerrado, quando estivermos nos referindo ao cerrado enquanto tipo vegetacional, isto é, do campo limpo ao cerradão - aqui há um complexo de biomas, bioma dos campos tropicais, das savanas e das florestas estacionais; e 3) cerrado sensu stricto, quando estivermos nos referindo a uma das fisionomias savânicas do cerrado sensu lato. É importante usarmos tais termos de forma precisa e acurada para que definamos aquilo que pretendemos estudar e para que conservemos esse complexo de biomas, com toda a biodiversidade que compõe o cerrado.

\section{Agradecimentos}

Agradeço ao Prof. Dr. Waldir Mantovani, pelas longas discussões que tivemos sobre o assunto e por suas leituras e sugestões.

\section{Referências Bibliográficas}

BOURLIÈRE, F. \& HADLEY, M. 1983. Present-day savannas: an overview. In Ecosystems of the world - tropical savannas (D.W. Goodall, ed.). Elsevier, Amsterdam, p.1-17.

BOX, E.O. \& FUJIAWARA, K. 2005. Vegetation types and their broad-scale distribution. In Vegetation ecology (E. van der Maarel, ed.). Blackwell, Oxford, p.106-128.

CLAPHAM Jr., W.B. 1973. Natural ecosystems. McMillan, New York.

COUTINHO, L.M. 1978. O conceito de cerrado. Rev. Bras. Bot. 1(1):17-23.

COUTINHO, L.M. 2006. O conceito de bioma. Acta Bot. Bras. 20(1):1-11.

COX, C.B. \& MOORE, P.D. 2009. Biogeografia: uma abordagem ecológica e evolucionária. Livros Técnicos e Científicos, Rio de Janeiro.

CRAWLEY, M.J. 1989. Plant ecology. Blackwell, Oxford.

DAJOZ, R. 1973. Ecologia geral. Vozes, Rio de Janeiro.

HURLBERT, S.H. 1971. The nonconcept of species diversity: a critique and alternative parameters. Ecology 52(4):577-586.

JOLY, C.A., AIDAR, M.P.M., KLINK, C.A., McGRATH, D.G., MOREIRA, A.G., MOUTINHO, P., NEPSTAD, D.C., OLIVEIRA, A.A.; POTT, A.; RODAL, M.J.N. \& SAMPAIO, E.V.S.B. 1999. Evolution of the Brazilian phytogeography classification systems: implications for biodiversity conservation. Ci. e Cult. 51: 331-348.

MAAREL, E. van der. 2005. Vegetation ecology - an overview. In Vegetation ecology (E. van der Maarel, ed.). Blackwell, Oxford, p.1-51. 
Batalha, M.A.

MYERS, N., MITTERMEIER, R.A., MITTERMEIER, C.G., FONSECA, G.A.B. \& KENT, J. 2000. Biodiversity hotspots for conservation priorities. Nature 403(6772):853-858.

ORR, D.W. 1999. Verbicide. Conserv. Biol. 13(4):696-699.

OXFORD. 1996. A dictionary of Biology. Oxford University, Oxford.

OXFORD. 2004. A dictionary of Ecology. Oxford University, Oxford.

PETERS, R.H. 1991. A critique for Ecology. Cambridge University, Cambridge.
RAUNKIAER, C. 1934. The life forms of plants and statistical plant geography. New York, Arno.

SÃO PAULO (Estado). 2009. Lei no. 13.550: dispõe sobre a utilização e proteção da vegetação nativa do Cerrado no Estado e dá providências correlatas. São Paulo, Assembleia Legislativa do Estado de São Paulo.

TALLIS, G.H. 1991. Plant community history: long-term changes in plant distribution and diversity. Chapman and Hall, London.

WALTER, H. 1986. Vegetação e zonas climáticas. EPU, São Paulo.

WOODWARD, S.L. 2008. Introduction to biomes. Greenwood, Westport.

Recebido em 23/09/2010 Versão reformulada recebida em 09/11/2010

Publicado em 31/01/2011 